\title{
The appearance of the electrical appliances product design and consumer aesthetic psychological analysis of the correlation
}

\author{
Hu Jie
}

College of Technology and Art Jingdezhen Ceramic Institnte, 333000

\begin{abstract}
Key words: Appliances appearance design; Consumers; Aesthetic psychology
\end{abstract}
\begin{abstract}
In today's rapid economic development, people's living standards improve, people's material life become rich and colorful, People's demands for material life are getting higher and higher, people's living environment to living, furniture, supplies and so on have higher requirements. Consumers of electrical appliances product appearance modeling design has aesthetic requirements, the purchase of electrical appliances product first of all to pay attention to whether Conform to their own aesthetic. Designers of the electrical appliances product design first take into account the appearance of the shape is in line with consumer psychology, this article mainly from the consumer's aesthetic psychology to talk about the importance of the appearance of the electrical appliances product design, analysis of the appearance of home appliances design and consumer aesthetic psychology of the relevance.
\end{abstract}

\section{Introduction}

In today's rapid development of market economy, with the continuous improvement of people's living standard as well as people pursuit of material comforts in life, at this stage of home appliances is not only to meet people's focus on the practicality of home appliances, but also people pursue the appearance of the electrical appliances product modeling whether to meet their own aesthetic psychology. In home appliances industry, More and more companies to follow people's emphasis on home appliance product outward appearance modeling design, the design of home appliances began to tend to aesthetic requirements, and only immediately follow the consumer's purchase of psychology to produce people's favorite home appliances. Under the impetus of the economic globalization, cultural exchanges between the countries in collision, people begin to going global for electrical appliances product design, designers hold consumer demand for electrical appliances product appearance modeling, are trying to design the people satisfied and happy to buy home appliance products.

\section{Consumers' aesthetic on the importance of the home appliance product outward appearance modeling design}

\subsection{Meet the needs of consumers}

For the design of the electrical appliances product, the initial starting point is the function of electrical appliances product. As consumer aesthetic psychological changes, attaches great importance to the appearance of home appliances design. At present about the overall design of the electrical home appliances products, in addition to the basic function, more attention to the appearance of the electrical appliances product aesthetic function, the design of the electrical appliances product to satisfy the consumers' aesthetic demand, can bring good psychological enjoyment for consumers. Therefore, the appearance of home appliances design to the beautiful shape and the appropriate color together, to meet the aesthetic psychology of consumers, thus driving the purchasing power of consumers, obviously, the appearance of home appliances design in line with the aesthetic psychology of consumers to become the actual needs of consumers.

\subsection{The unity of practical and aesthetic}

With the continuous improvement of people's living standard, people use the appliance is getting higher and higher, home appliances can be said to be a wide variety, the appearance of beautiful and 
more advanced function of home appliances will replace some appliances that cannot satisfy people aesthetic psychology. The designer to the design of electrical appliances product can't be unrealistic, appliances color choice is not subjective imagination, home appliances come from people's real life, of course, in the process of design inspiration also comes from life. Home appliance product design is not the innovation and leading the trend, comply with the aesthetic psychology of consumer is right. In a real understanding of consumer psychology, the combination of practicality and aesthetics in the design process, design good products meet consumer psychology.

\section{The real connotation embodied in the appearance of the electrical appliances product modeling design}

\subsection{The diversity of shape}

In the design of home appliance products, the appearance of home appliances design is the idea of home appliance external characteristic design, of course, another important aspect of electrical appliances product is the use of the function is complete. In the light of consumer demand for electrical appliances product aesthetic, designers add a variety of elements in the shape design, the appearance of the electrical appliances product such as color, line, texture effectively together, to meet the aesthetic psychology of consumers. On the design of the home appliance product outward appearance modeling should attach great importance to the characteristics of diversity, in terms of design, if the designer don't realize the diversified characteristics of outward appearance modeling, it is difficult to meet the aesthetic needs of consumers, for consumers don't have any attractive ${ }^{[1]}$.

\subsection{The Real Connotation and the Fusion of Appearance}

The most basic function of electrical appliances product is practical, it can also be the real connotation of the electrical appliances product, outward appearance modeling design pursuit of aesthetic, consumer pursuit of electrical appliances product visual enjoyment, let consumers are willing to go to buy. However, the practical function of home appliances as a real connotation in the home appliance products can not be ignored, designers can reflect the true meaning of home appliances in the appearance of the design. This does not affect the aesthetic and can satisfy the real connotation of practicality, let the consumer realize the connotation of the electrical appliances product design. For example, the appearance of the electrical appliances product modeling design is not blindly pursue aesthetic, to properly combine the connotation of home appliances design, through the appearance of home appliances show the true meaning of home appliances. The appearance of home appliances design color to give priority to with consumers, color also can be a factor in whether consumers to buy, the designer has grasped the consumer's preferences for color, the color is applied in the design of the shape. The use of household electrical appliances environment is based on the design of consumer interior color to coordinate the choice, to give people a warm feeling. With the consumer's aesthetic psychology and designer design of home appliances with color, consumers of home appliances in the choice of color will be the same value with the aesthetic, home appliances through the shape and color to show the design of the personality, show the uniqueness of appliance products.

\section{The appearance of home appliance products design and use of the integration of functions}

To a certain extent, the appearance of home appliances design is a kind of pursuit of art, is the designer in the course of practice combined with artistic and aesthetic results. The pursuit of artistic aesthetics is based on the development of innovation, the pursuit of home appliances is the pursuit of art, in use can bring better psychological experience. Designers of the electrical products of home appliances to explore the connotation and shape of the organic combination. To allow consumers in the course of the use of the real experience of the appearance of the design to bring the spirit of the enjoyment and use of the connotation of the comprehensive enjoyment.

\subsection{The integration of electrical appliances product function}


Designers in the pursuit of aesthetic needs of consumers at the same time did not ignore the use of home appliances function, the core of home appliances is the use of features, this is a view that people are not subject to any external psychological influence, it is a rational understanding of the objective evaluation for household electrical appliances function. and the pursuit of electrical appliances product use function is stylist in the design of electrical appliances product specific design aspect of its ongoing reform, therefore, the appearance of the electrical appliances product modeling design and use function should be comprehensive consideration, to achieve the function of the electrical appliances product integration.

\subsection{Electrical appliances product outward appearance modeling design aesthetic}

As people's material life level unceasing enhancement, people pay attention to the appearance of home appliances, the appearance of the electrical appliances product form become the important factors that affect the product design. The appearance of home appliances design and beauty of the combination of form, become a kind of consumption activities. In the form of the subjective consciousness of consumers become dominant, when buying electrical appliances product ignore the practical function, but the pursuit of psychological comfort and visual enjoyment, too much attention to the overall aesthetic of home appliance products.

\subsection{The experience of using household appliances}

The experience of the use of home appliances is characterized by the use of household electrical appliances in the process of consumers can bring a harmonious and comfortable feeling, and there is a kind of man-machine harmonious relationship. Consumer favorite appearance modeling design, comfortable color collocation and the use of more comprehensive function can make consumer satisfaction, and some designers through product design features to deliver targeted emotional information. In the experience of the consumer many times, whether it is the appearance of home appliances modeling, color matching, the use of features and emotional information transmission are virtually to bring a wonderful experience characteristics, this design is the perfect combination of form and function. Let the consumer is willing to buy, and can pass the beauty of love to the consumer in the process of use, to form a holistic experience ${ }^{[2]}$.

\section{Conclusion}

To sum up, with the continuous improvement of people's living standards, people pursuit of home appliance product outward appearance modeling design more than the pursuit of electrical appliances product use function, people's consumption concept into the pursuit of aesthetics. In actual design application, the appearance of home appliances design after understanding the consumer aesthetic psychology, according to the practical development and innovation, market is the real test of the electrical appliances product design success or failure. The excellent design is to add a single product into a unique emotion, in the appearance of the product modeling, color matching, material selection and the use of functional aspects get on a comprehensive overall consideration, so that home appliances to achieve a more perfect combination to a certain extent. It is obvious that home appliance industry in the coming years, the aesthetic psychology of consumers has become a factor in the design of home appliances can not be ignored.

\section{References}

[1] Zhang Jun. The appearance of the electrical appliances product design and consumer aesthetic psychological analysis of the correlation [J]. Journal of Hubei institute of adult education, 2015, 21 (4): 80-82.

[2] Yang Ji. Analysis and application of emotional factors in product design [J]. Science and Technology Information, 2009, (29): 339-340. 